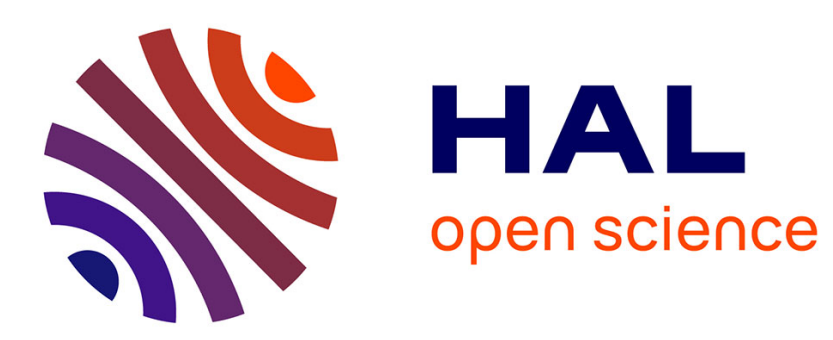

\title{
Phonological deficits in French speaking children with SLI
}

\author{
Christelle Maillart, Christophe Parisse
}

\section{To cite this version:}

Christelle Maillart, Christophe Parisse. Phonological deficits in French speaking children with SLI. International Journal of Language and Communication Disorders, 2006, 41 (3), pp.253-274. halshs00091002

\section{HAL Id: halshs-00091002 https://shs.hal.science/halshs-00091002}

Submitted on 5 Sep 2006

HAL is a multi-disciplinary open access archive for the deposit and dissemination of scientific research documents, whether they are published or not. The documents may come from teaching and research institutions in France or abroad, or from public or private research centers.
L'archive ouverte pluridisciplinaire HAL, est destinée au dépôt et à la diffusion de documents scientifiques de niveau recherche, publiés ou non, émanant des établissements d'enseignement et de recherche français ou étrangers, des laboratoires publics ou privés. 


\section{Phonological deficits in French speaking children with SLI}

Christelle Maillart (1) and Christophe Parisse (2)

Running head: Phonological deficits in children with SLI

Affiliation: (1) UCL-PSP/CODE, Louvain-la-Neuve, Belgique

(2) LEAPLE-INSERM, UMR 8086, Villejuif, France

Address for correspondence:

Christelle Maillart

Unité Cognition \& développement

Faculté de Psychologie et des Sciences de l'Education

10, place cardinal Mercier

1348 Louvain-la-Neuve 


\begin{abstract}
Background. This study investigated the phonological disorders of French-speaking children with SLI in production.

Aims. The main goal of this paper was to confirm whether children with SLI have limitations in phonological ability as compared to normally-developing children matched by MLU and phonemic inventory size. A number of researchers have obtained findings pointing in this direction, including Bortoloni and Leonard (2000), Orsolini et al. (2001), and Aguilar-Mediavilla et al. (2002), who obtained the most detailed results, but the conclusions have never been tested on French-speaking children. The second goal of the paper was to find out whether characteristic features of the French language are reflected in the nature of the children's phonological disorder.
\end{abstract}

Methods and procedures. The spontaneous language of 16 children with SLI and 16 control children matched on MLU and phonemic inventory size (NLD group) was analysed using different measures bearing on utterances, words, syllables and phonemes. In both SLI and NLD groups, the children were distributed into two different subgroups, on the basis of their MLU, with controlled phonemic inventory size.

Outcomes and results. The results supported a specific limitation in the phonological abilities of French children with SLI, as has already been demonstrated for English, Hebrew, Italian, and Spanish-Catalan. However, two unexpected results were also obtained. Firstly, a significant difference between children with SLI and control children could only be found for older children (MLU above 3), not for younger children with MLU below 3. This was true for all measures.

Conclusions. This finding highlights the importance of having a developmental perspective and needs to be confirmed through a longitudinal study.

Secondly, deficits were much more significant at the phoneme level than at the syllable level. This may be explained by the fact that the pronunciation of syllables in French is very homogenous, making them easier to segment.

Key words: specific language impairment, language disorders, children with SLI, phonology, French 
Phonological deficits in French speaking children with SLI

\section{Introduction}

Numerous hypotheses have been proposed to take into account the deficits of children with specific language impairment (SLI). The five major ones are: acoustic processing deficit (Tallal, Stark, \& Mellits, 1985; Benasich \& Tallal, 2002), phonological deficit (Leonard, Dromi, Adam, \& Zadunaisky-Ehrlich, 2000; Chiat, 2001), grammatical deficit (Rice \& Wexler, 1995; Clahsen, Bartke, \& Goellner, 1997; van der Lely \& Stollwerck, 1997), short term memory deficit (Gathercole \& Baddeley, 1990), and processing capacity deficit (Leonard, McGregor, \& Allen, 1992) - (see Bishop, 1992; Leonard, 1998, for a full review). Of course, these deficits could also have a multi-factor origin (Bishop, Carlyon, Deeks, \& Bishop, 1999), or involve two of the above factors. For example, a deficit in phonological representations could result from both phonological and processing capacity deficit. It should also be noted that most children with SLI exhibit multiple deficits (perception, phonology, syntax, memory, and processing capacity). The crucial question is whether some deficits are simply a result of other deficits or whether they are at the source of the children's problems.

The aim of this article is to identify whether there is a specific phonological deficit that could be at the root of the children's problems. Some studies have already hypothesised the existence of such a deficit (Joanisse \& Seidenberg, 1998; Bortolini \& Leonard, 2000; Leonard et al., 2000; Owen, Dromi, \& Leonard, 2001). Chiat (2001) goes even further and suggests that an initial phonological deficit is at the root of subsequent lexical, syntactic and semantic problems in children with SLI. She proposes that 'the children with SLI have reduced access to phonological details within rhythmic structures which are required for the establishment of lexical forms and syntactic structures. (...) The hypothesised deficit might be expected to span all levels of phonological processing, with the deficit at each level feeding into and fed by the deficit at other levels in ways which change in the course of development (p.124).' Other theories hypothesise that phonology is at the source of syntactic disorder, for example Joanisse (2004). Whatever the theoretical implications of a phonological theory of SLI, the existence of an initial phonological problem implies that it should be possible to exhibit purely phonological mismatches that cannot be explained by lexical and semantic factors.

This means that children with SLI should present a significantly greater number of phonological errors than other children with the same language development. If the hypothesis of an initial phonological deficit is correct, the deficit should be observed independently of the child's mother tongue, even though there could be differences from one language to another. It is thus important to find information from crosslinguistic studies about children with SLI.

\subsection{Previous studies about phonological difficulties in children with SLI}

Many studies on children below age three with a phonological deficit in production have compared the phonological performances of children with SLI and control children of the same age. For example, the language production of late-talkers 
aged 24 months (Stoel Gammon, 1989), aged 24 up to 31 months (Rescorla \& Ratner, 1996), or aged 34 months (Paul \& Jennings, 1992) were compared to the production of normally developing age-mates. This comparison showed that the late-talkers presented quantitative delays with regards to some phonological measures such as the complexity of their syllable structure or the size of their phonemic repertoire (see for Roberts, Rescorla, Giroux, \& Stevens, 1998, a review). Although these studies objectified a quantitative developmental delay in children with phonological deficit, they also indicated that the production of these children was not qualitatively different to the production of younger control children. For example, no specific type of errors or phonological processes could be found in SLI or control children. The impaired phonological development could thus be considered as delayed rather than deviant, and actual deviant development needs to be more clearly proven.

Some studies have employed direct comparisons between groups of younger normally-developing children and older children with SLI matched on a language development measure. Such comparisons are very helpful as they can help to identify the true source of developmental language delays and difficulties. For example children with phonological difficulties also proved to have morphosyntactic development delays (Shriberg \& Kwiatkowski, 1994). If the phonological problems of children with SLI are part of a more general linguistic deficit, no difference should be found between children with the same level of syntactic development, which in most cases is assessed using a general purpose measure such as the mean length of utterance (MLU). If, on the other hand, phonological differences are found in children with comparable syntactic development, then this would prove phonological development to be a particular source of difficulty for children with SLI. This finding would have important theoretical consequences and phonological weakness would have to be taken into account when studying morphosyntactic development. It would add support to theories linking the difficulties of children with SLI to the existence of a specific impairment in the processing of language input (Chiat, 2001; Owen et al., 2001) and would go against theories which hypothesize the existence of a specific grammatical impairment (Gopnik, 1997; van der Lely \& Christian, 2000).

Other studies have investigated the phonological productions of young children with SLI compared to those of normally-developing children matched by MLU. For example, Schwartz, Leonard, Folger and Wilcox (1980) compared three children aged from 2;7 to 3;7 with three control children aged 1;8 and matched by MLU (mean MLU 1.14) in a spontaneous language task. In spite of significant individual variation, the absence of any group effect suggested that the phonological development of children with SLI and normally-developing children was broadly similar. However studies investigating other children have found differences in the phonological development of children with SLI and control children matched by MLU. Bortolini and Leonard (2000) compared the productions of nine Englishspeaking children with SLI aged from 3;7 to 5;9 to those of nine control children aged from 2;5 to 3;3 and matched for MLU (respectively $\mathrm{M}=3.75$ (S.D. 0.54) and $\mathrm{M}=$ 3.72 (S.D. 0.55)) and consonant inventory (respectively $\mathrm{M}=16$ (S.D. 1.22) and $\mathrm{M}=$ 16.44 (S.D. 1.94)). They showed that the children with SLI were less accurate in their word productions and demonstrated greater phonological inconsistency. Moreover, the children with SLI were poorer than the younger control children in the use of nonfinal weak syllables, word final consonants and word final consonant clusters. These results were confirmed by a second experiment which compared twelve Italian- 
speaking children with SLI aged from 4;1 to 7;0 and twelve control children aged from 2;6 to 4;0 matched for MLU (respectively $\mathrm{M}=3.76$ (S.D. 0.66) and $\mathrm{M}=3.73$ (S.D. 0.66)) and consonant inventory (respectively $\mathrm{M}=16.92$ (S.D. 1.93) and $\mathrm{M}=$ 17.42 (S.D. 0.79)). Once again, words produced by the children with SLI were less accurate and they had additional difficulties with initial consonants and non-final clusters. This crosslinguistic study provides strong evidence to support the existence of specific phonological limitations in children with SLI, phonological abilities lagging behind other language abilities which are themselves developing slowly.

Another study (Aguilar-Mediavilla, Sanz-Torrent, \& Serra-Raventos, 2002) compared five young Spanish-Catalan bilingual children (MLU: 1.2-2.3.) aged 3;0 to $4 ; 0$ with five control children aged $1 ; 6$ to $2 ; 8$. For the vast majority of the phonological variables studied (i.e. PCC, syllabic patterns, etc.), no significant differences were observed between those two groups. However, there were a small number of variables for which there were differences: children with SLI produced more mismatches on vowels (PVC), nasal consonants and stops; although the CV structure was better produced than other syllable structures, it was less accurately produced by children with SLI than by control children; finally, they produced on average fewer correct words. The fact that specific phonological difficulties were observed for English, Italian, Spanish, and Catalan suggests that the phonological weaknesses are not related to the phonetic properties of a specific language but are evidence of a more universal phenomenon.

There is of course a possibility that these phonological limitations could simply be accounted for by grammatical difficulty. Indeed, in languages with an important phonology/morphology interface (see Bernhardt \& Stemberger, 1998, Chapter 9, for a crosslinguistic presentation of the development of the morphology/phonology interface), phonological limitations could be a consequence of grammatical disorder. If a grammatical disorder blocks or impairs the production of specific morpheme, then this could wrongly be interpreted as a phonological deficit.. In Hebrew, for example, phonology and morphology are highly inter-connected and phonological and morphological weaknesses were indeed observed in Hebrewspeaking children with SLI (aged $4 ; 2$ to $6 ; 1$ ) when they were compared to younger control children (aged 2;8 to 3;11) showing the same MLU (Owen et al. 2001). However, the pattern of errors observed could not be explained by grammatical problems since specific phonological difficulties were observed with phonemes and phoneme sequences without any grammatical function (for example, phonological mismatches and consonant cluster reduction).

In summary, this brief overview of the literature has attempted to demonstrate that for a range of languages (English, Italian, Hebrew, Spanish, and Catalan), there are significant phonological differences between children with SLI and control children matched on language level. The precise nature of these differences varied from one language to the other. For example, only the study of Spanish and Catalan identified a weakness with vowels. In addition, the phonological weaknesses identified could not be only explained by grammatical difficulties. These findings provide tentative confirmation of one of the hypotheses formulated by the phonological theory, namely that children with SLI present severe phonological disorders. 
It should be mentioned that the only study (Schwartz et al., 1980) which identified no difference between SLI and control children was conducted on very young children (control children $<$ two-year-olds). The presence of specific phonological properties could thus depend partially on the age of the observed children and would only be observable on older children. Indeed Beers (1995) work points in this direction, showing that some differences between SLI and control children seem to emerge later. In her longitudinal study, Beers compared the proportion of unusual phonological processes in children with SLI aged 4 to 6 years and control children aged from 1;3 to 2;2 years. Younger children with SLI could not be distinguished from the control children. However, while the latter rapidly increased their productions, children with SLI persisted in producing phonological mismatches. Significant differences between the groups emerged from age $5 ; 0$ to age $5 ; 6$. It is thus possible that differences in the studies presented here, specifically the lack of significant differences in the studies on younger children as compared with the deficit found in the studies of children with higher MLU's, are merely a reflection of differences in language level. Matching procedure between children with SLI and control children

In many studies, MLU has been used as a way of matching children with SLI and control children. Despite some limitations (Chabon, Kent-Udolf, \& Egolf, 1982; Klee \& Fitzgerald, 1985), MLU remains an efficient tool for assessing the difference between children with SLI and normally-developing children (Klee, Schaffer, May, Membrino, \& Mougey, 1989). It is efficient as the order it indicates remains stable across different situations (Bornstein, Painter, \& Park, 2002), but it can change for the same child from one situation to another (Bornstein et al., 2002). This may cause a problem when the elicitation procedure is not exactly the same for all groups of children (see below).

Despite its lack of precision, MLU has one advantage over more complex language evaluation procedures (a language test for example). It is -at least when computed in words- not highly sensitive to the quality of speech, which is important in the present study. Nor is it highly sensitive to the child's vocabulary, which is important because it would otherwise be difficult to compare four-year-olds to eightyear-olds (or children aged 2;3 to children aged 4;0). Finally, despite MLU's lack of precision, the errors it produces do not favour the less talkative children. Indeed, children with SLI who tend to be aware of their difficulties will tend to speak less and avoid complex constructions. This results in an underestimation of the child's true speech level, so control children matched with MLU have a lower language development level than with other matching methods. Finally, as MLU is widely used in the literature, using it makes research results more easily comparable with other work in the field.

The limitations of MLU lead some authors (Bortolini \& Leonard, 2000) to use an additional consonant inventory measure to compare the level of the children with SLI and the control children. Matching children for consonant inventory will prove that if there is a difference in phonemic performance between the children, this will be due not to an inability to segment data, but to use and manipulate the segments. Using the procedure also makes it more unlikely that phonological difference between children will be found and any differences found will be even more significant. 


\subsection{Purpose of the study}

To our knowledge, no study on phonological properties of children with SLI has ever been carried out for the French language. Therefore, the first objective of this work was to check whether French-speaking children with SLI produce as many phonological errors as their peers (matched on language level). The results obtained will make it possible to investigate the nature of the children's phonological difficulties in a crosslinguistic perspective. For example, given that the French language does not use a strong tonic stress, it seems unlikely that phonological difficulties found in French-speaking children could be explained by the existence of unstressed syllables.

The second objective of this work is to check whether phonological difficulties are consistent with throughout the development process, as it seems quite likely that age and language level may influence the children's phonological abilities. It is important to check whether the predicted effects (i.e. more phonological errors on children with SLI than in control children) are present as soon as children begin to combine words or whether they emerge later.

\section{Methods}

\subsection{Participants}

Thirty-two children participated in the study: 16 children with SLI and 16 NLD control children. All participants were French native speakers. The SLI group was divided into two groups on the basis of age and general language development. There was a large difference between the two groups in general language development and age (see Table 1). Two groups of control children corresponding to the two groups of children with SLI were selected on the base of their MLU. The selection procedure was done in two steps. In the first step, the average MLUs of the two SLI groups were computed, which gave two levels of language development (according to MLU): 2.4 and 3.7. The two MLU values were used to choose an average age for each of the control groups. MLU 2.4 corresponds to age 2;3 and MLU 3.7 to age 4;0. The second step consisted in selecting a set of control children aged 2;3, each matched for MLU with one child from the group of younger children with SLI. The same procedure was used to select a control group of children aged 4;0 for the older children with SLI group. This selection procedure ensured that there was a real developmental gap between the groups of younger and older children, regardless of the pertinence of measures such as MLU or phonemic inventory.

The phonemic inventory size of the children was measured as a way of confirming whether the children in the current study match Bortolini and Leonard's (2000) conditions. Half the children had a low MLU (SLI: $M=2.4$, Controls: $M=$ 2.7) and a small phonemic inventory (SLI: $M=18$, Controls: $M=19$ ) and the other half had a high MLU (SLI: $\mathrm{M}=3.7$, Controls: $\mathrm{M}=3.7$ ) and a larger phonemic inventory (SLI: $M=22$, Controls: $M=23$ ). The phonemic inventory may appear small as the maximum value for phonemic inventory in French is 31 (18 consonants, 10 vowels, and 3 semi-vowels), but the inventory was computed on the basis of a sample of spontaneous language, which minimizes its value. 


\section{Insert table 1 about here}

Children with SLI : All children had been previously diagnosed as language impaired by a multidisciplinary team. The diagnosis included a medical exam (audition and vision), as well as neuropsychological and speech - language investigations. All of them satisfied the classical exclusion criteria for an SLI diagnosis (Stark \& Tallal, 1981). They scored within the average range on the Leiter International Performance Scale (Roid \& Miller, 1993) and the non-verbal scale of the Wechsler Intelligence Scale for Children WISC III (Wechsler, 1996) and they also demonstrated hearing and oral motor functioning within normal limits and no signs of emotional disturbance.

Control children with NLD. Two groups of children with normal language development served as control for MLU. These children were recruited at nursery schools and kindergartens.

An analysis of variance was carried out with MLU and size of the phonemic inventory as dependant variables and with type (SLI vs. Controls) and language development (high vs. low) as between-subjects independent variables to check the group matching. As expected, an effect of language development was observed for MLU, $F(1,28)=10.28, p=.003, \eta^{2}=.27$, and for size of phonemic inventory, $F(1$, $28)=9.401, p=.005, \eta^{2}=.25$. No effect of type was found, either for MLU, $F(1,28)$ $=.120, p=.73$, or for phonemic inventory, $F(1,28)=.151, p=.64$. No significant interaction effect was found between type and language development, $F(1,28)=.205$, $p=.65$, for MLU and $F(1,28)=.763, p=.37$, for size of phonemic inventory. These results confirmed that there was no difference between the groups of SLI and control children as regards their language level (in as far as MLU is a good indicator of language level), and particularly as regards their syntax and phonemic level. They also confirmed that there was a developmental difference in both measures between the groups of younger and older children. This means that any difference found in the study for children of the same age cannot be explained by differences in syntactic or phonemic development. On the other hand, , potential differences between age groups may be attributed to differences in development.

\subsection{Procedure}

\subsubsection{Data gathering}

The aim of the recording procedure was to obtain spontaneous language production. All data gatherings used the same principle: an adult observer asked the child questions to stimulate language production. As subjects' ages varied from two to twelve, the nature of the questions and situations was not the same for all children. The same procedure was used for the two groups of children with low MLUs (Le Normand, 1986). In this procedure, children are in a play situation. Whenever they are speaking, they are never interrupted and may speak for as long as they want. A familiar adult observer (usually one of the parents) is present and plays with the child. The role of the adult observer is to ask the children questions if they are not producing much language. The length of the recording is standardized to 20 minutes. For children with high MLUs, the child is asked questions by a professional speech therapist following the procedure described by Evans and Craig (1992). The speech 
therapist asked each child questions about its home, family and school. For control children, the procedure used was the 'Bain des poupées' from a normalized languagetesting tool (Chevrie-Muller, Simon, Le Normand, \& Fournier, 1997). During this procedure, a professional speech therapist plays with the child using a standardized set of toys in a standardized situation: giving a bath to two dolls. The speech therapist asks the children specific questions about the process involved (taking a bath) and about what the child does at home in a similar situation. The child answers the question and the interview goes on until the whole set of questions is finished. This procedure is similar to that used for SLI children. For most of the older children groups (SLI and controls), the length of the interview was comparable to the length of the younger children's recording, but for some children it was much longer, so the phonetic transcription was tailored to a maximum length of 135 utterances.

MLU was computed in words, without taking into account any word ending. This is the most useful way of computing MLU for young French children for three reasons: first, the results obtained are comparable with studies in other languages which used the same measure (Bortolini \& Leonard, 2000; Aguilar-Mediavilla et al., 2002); second, the most common morphological markings pronounced in French are made redundant with the use of an article, a pronoun or an auxiliary, so using MLU computed in words avoids counting the same morphological information twice and finally, morphological markings (mainly on verbs) that are not redundant are nearly never used by young children (especially before age four), with the exception of story telling situations which were not used in this study.

One might assume that using three different elicitation procedures could lead to differences between the resulting corpora. The use of different procedures was necessary because of the large differences in age between children and the necessity of maintaining the children's interest. But there are two reasons for believing that these different procedures might nevertheless yield comparable results. First, as it is the phonological structure that is studied here, and not lexicon or semantics, the speech data obtained from these conversational samples is more likely to be linguistically and psychometrically robust (Shriberg, 1993). Second, although the procedure used with the younger children is a play situation, the goal of this procedure was to obtain the maximum amount of material in 20 minutes only. For this reason, most of the time the adult was asking the child questions about was she was doing, or what she was going to do with such and such an object (always from the same set). What results from this is much more akin to an interview than to free play at home. The similarity between the two procedures has in fact been demonstrated through the preliminary results of an ongoing study which used the two protocols with two sets of three-year-olds. The 40 children that underwent the Le Normand procedure had an average MLU of 3.58 (S.D. $=0.95)$ and the 37 children that underwent the Chevrie \& al. procedure had an MLU of 3.26 (S.D. $=1.03$ ). There was no significant difference between the two groups, $t(75)=1.406, p=0.16$.

For the two groups of older children, although the questions asked were not the same, the same procedure was followed, so that in all cases the child had to choose her own words and phrasing. It is clear that despite all these precautions, small differences may remain between the elicitation procedures and these may explain the differences between the groups. But it is not certain that using exactly the same procedure would not also have an effect on the results, as a procedure than may be too 
simple (or too complex) for a given age group can lead to abnormal performances than may induce even greater differences that the three procedures used here.

\subsubsection{Phonemic transcription}

Most of the transcriptions were done by the two authors of the paper. For some recordings, the transcription was first done by trained specialists and later extensively checked by the two authors. All cases of disagreement between transcriptions were discussed until full agreement was reached. Most cases of disagreement were in the tagging of vowels subject to regional variations (see below). The other problems were mostly about the transcription of codas (/I / and /R /), which are often difficult to perceive. Where there was any doubt, the child was considered to have produced the standard expected adult pronunciation. Transcription was done using a phonemic approach rather than a phonetic approach to allow a certain leeway in the pronunciation. Achieving a 100\% success rate in phonetically tagging a large corpus is undeniably a highly challenging task. Transcription adopted the CHAT format (MacWhinney \& Snow, 1985; MacWhinney, 2000) and for the phonemic transcription, the SAMPA phonetic alphabet was taken (see Appendix), using the full set of French phonemes, which includes 18 consonants, 3 semivowels, and 16 vowels. As some of the contrasts between vowels are becoming obsolete in modern French language and are subject to regional variants, four pairs and a triplet of vowels were reduced to single phonemes for all subsequent analyses, which left a set of ten different vowels, including three nasal vowels. The full set of phonemes used in the transcripts can be found in the Appendix.

After phonemic transcription, a model line (\%mod tier in the CHAT format) was added for each phonemic line transcribed that contained the correct phonemic target. This information was thoroughly checked by the two authors as it was used for automatically computing results of data analysis. All types of contractions were considered as correct, as well as some consonant reductions in front words beginning with a vowel, as this represents standard oral French language (Blanche-Benveniste, 1990). For example, forms such as 'pti' for 'poti (petit=small)', contractions such as ' ja' for 'ilija (il y a = there is)', and consonant reduction such as 'i tõb' for 'il tõb (il tombe $=$ he falls down).

\subsection{Analysis}

Analyses were conducted at four levels, corresponding to four different levels of linguistic analysis: utterance level, word level, syllable level, and phoneme level.

Analysis at utterance level follows Rescorla and Ratner's (1996) criteria. The number of vocalizations, phonemically transcribable utterances, and fully intelligible utterances were computed for each child. Vocalization consisted of any speech sound made by the child, whether phonemically transcribable by the transcriber or not. Nonspeech sounds such as coughs, song or laughs were not taken into account. Phonemically transcribable utterances consisted of utterances that could be fully transcribed into phonemes, even if their meaning could not be fully understood. Fully intelligible utterances referred to utterances that were fully understood by the 
transcriber, and for which a complete phonetic model could be be constructed, which was not the case for the phonemically transcribable set of utterances.

Analyses at word level consisted in simply counting the number of words which exactly matched the phonemic model. Words that could be understood but belonged to a partially intelligible utterance were taken into account. A word was considered correct if all phonemes matched exactly the model. However, if the pronunciation of a word followed an adult variant, it was considered as correct and hesitations and rephrasals were not counted as errors. These conventions were also valid for syllable and phonemic analysis.

A syllabification software program was specially designed by the second author to enable automatic computation of syllables for all the words produced and for all the word models. Syllabification was carried out on phonemic transcriptions, which is a much easier task than syllabification on orthographic transcriptions. For example, all the ambiguous cases of liaison had already been solved manually during the phonemic transcription. A manual check of the syllabification software performed on one tenth of all the multisyllabic words revealed no syllabification errors, so the real error rate is probably very low. After syllabification, the phonetic value of each syllable was transformed into a syllable frame (V, CV, VC, CVC ...). These syllable frames were then used to compute statistics of syllable use. The same syllabification process was applied to the phonological model lines, which creates syllable model lines. These lines were used to compute automatically statistics for correct syllable use.

The computation of the percentage of phonemes correct (PCC) is widely used in the literature. The version used here is described fully in Shriberg and Kwiatkowski (1982). It consists in counting how many correct consonants produced matched the target words, and then dividing this number by the sum of the number of consonants expected (produced or not) plus the number of unexpected consonants produced. The algorithm used to compute the percentage of vowels correct (PVC), and the percentage of phonemes correct (PPC) is similar. One simply replaces consonant by vowel in the algorithm above, or consonant by phoneme (= consonant + vowels + semi-vowels) - semi-vowels were taken into account in the PPC only. The existence of the model line in the transcription makes it possible to compute the PPC, PCC, and PVC automatically.

Analysis of phonemic transcription was performed using the tools available in the CLAN software of the CHILDES system when such tools exist. To reduce manual manipulation of data to a minimum, specific tools had to be designed to compute all phonetic variables (word, syllable, PPC, PCC, and PVC) automatically.

\section{Results}

\subsection{Utterance level}

The average values for number of vocalizations, of phonemically transcribable utterances (FIU), and of fully comprehensible utterances (FCU) are shown for each group in Table 2. The total number of number of vocalizations was 1,111 (FIU: 1047, 
FCU: 784) for the younger SLI children, 1,315 (FIU: 1242, FCU: 968) for the younger control children, 1,025 (FIU: 1019, FCU: 882) for the older SLI children, and 898 (FIU: 885, FCU: 867) for the older control children. The percentage of phonemically transcribable utterances and the percentage of fully comprehensible utterances were submitted to a variance analysis (ANOVA) with type (SLI vs. controls) and MLU (high. vs. low.) as between-subject variables. The results revealed a significant effect of MLU on percentage of phonemically transcribable utterances, $F(1,28)=16.89, p=.0003, \eta^{2}=.38$, and percentage of fully comprehensible utterances, $F(1,28)=15.56, p=.0005, \eta^{2}=.36$. In contrast, there was no effect of type $(F(1,28)=1.179, p=.28$, for FIU, $F(1,28)=1.507, p=.23$, for FCU) and no type/MLU interaction $(F(1,28)=.005, p=.94$, for FIU, $F(1,28)=1.359, p=.25$, for FCU). These findings show that for all the children, irrespective of type, the intelligibility of their utterances went up as their MLU increased.

\section{Insert Table 2 about here}

\subsection{Word level}

The full results for the percentage of words correctly produced are given in figure 1. This measure showed a significant effect for MLU, $F(1,28)=12.365, p=$ $.002, \eta^{2}=.30$, with high MLUs performing better than low MLUs, and for type (SLI vs. Controls), $F(1,28)=6.878, p=.02, \eta^{2}=.20$, reflecting the fact that children with SLI performed globally less effectively than their peers. However, these results had to be interpreted taking into account the presence of a significant type/MLU interaction, $F(1,28)=7.990, p=.009, \eta^{2}=.22$. This interaction was further investigated to compare the type effect within each MLU group. For the low MLU children, the type effect did not reach the significant level, $F(1,14)<.017, p=.89$. For the high MLU children on the other hand, the type effect was considerable, $F(1,14)=19.528, p=$ $.0006, \eta^{2}=.58$. The difference between control children and children with SLI emerged when these children produced longer utterances.

\section{Insert Figure 1 about here}

\subsection{Syllable level}

\section{Insert Table 3 about here}

Different variables were analysed: the number of added or omitted syllables, the distribution into syllable frames, and the percentage of correct responses for each syllable frame. The number of added or omitted syllables was low. Full results are given in Table 3. These results include the aggregate percentage of errors (additions and omissions) for plurisyllabic words only, produced or expected. A variance analysis with type (SLI vs. controls) and MLU (high. vs. low.) as between-subject variables was computed for all variables in the results. Table 3 includes all exact computed values. There was a significant effect of type for all variables except for omission of final syllables. Compared to their language level peers, children with SLI were found to add and omit more syllables. An MLU effect was found for all errors and for some omissions. No significant effect was found for additions, for initial 
omissions, and for final omissions. No interaction effect was found between type and MLU.

\section{Insert Table 4 about here}

Table 4 shows the distribution of the most frequent syllable frames produced. An analysis of variance (ANOVA) was performed on each syllable structure with type and MLU as between-subjects variables. All statistical values computed are given in Table 4. The proportion of CV syllables decreased significantly as MLU increased, as suggested by the MLU effect. No effect of type was found, and no type/MLU interaction of . There was a similar decreasing effect for $\mathrm{V}$ syllables, with a significant MLU effect. Children with SLI produced more V syllables and there was a type effect, but no type/MLU interaction effect. There was no effect at all for VC syllables. The proportion of CCV syllables increased with MLU, but there was no effect of type, and no type/MLU interaction. There was a similar increase for CVC syllables, with a similar effect of MLU, but also an effect of type, with control children producing more CVC syllables, and no type/MLU interaction. Finally, other syllable types behaved in a similar way to CCV syllables, with a significant increasing effect with MLU, but no effect of type, nor any interaction effect. In others terms, the proportion of simple syllables $(\mathrm{CV}, \mathrm{V})$ decreased with MLU while more complex syllabic structures (CCV, CVC) increased. Children with SLI did not differ globally from control children. However, compared to control children, the children with SLI produced a higher percentage of V syllables and a lower percentage of CVC syllables.

\section{Insert Table 5 about here}

Table 5 shows the percentages of correct syllable frame, for each category of syllable frame. Once again, an analysis of variance (ANOVA) was performed on each syllable structure with type and MLU as between-subjects variables and all statistical values computed are given in Table 5. The number of correct responses for CV syllables was higher for older children than for younger children, with a significant MLU effect. It was also higher for control children that for children with SLI, with a significant type effect, but there was no type/MLU interaction. For V syllables, there was no significant MLU or type effect, but there was an type/MLU interaction effect . For VC syllables and CCV syllables, there was no significant effect at all. For CVC syllables, the number of correct responses was higher for older children than for younger children, with a significant MLU effect. However, there was no type effect, nor any interaction between MLU and type. Finally, for the other syllable frames, there was a similar increase in correct responses for older children, with a significant MLU effect, but no effect of type. However, there was type/MLU interaction . In summary, few differences between the two groups were found. Only for CV syllables did the control children perform better than the children with SLI, irrespective of MLU, while only control children with high MLU performed better for V syllables and other syllables frames. .

\subsection{Phoneme level}

Insert Table 6 about here 
Table 6 shows the values for percentage of phonemes correct, consonants correct and vowels correct. As previously, analyses of variance were conducted with type and MLU as between-subjects variables: full results are given in Table 6. An effect was found for type for all these variables, percentage of phonemes correct (PPC), percentage of consonants correct (PCC) and percentage of vowels correct (PVC), with control children performing better than children with SLI. Similarly, a MLU effect was significant for all variables, indicating that these percentages increased with the MLU. Finally, for PPC and PVC, but not for PCC, these main results had to be questioned for the presence of a significant type/MLU interaction. As suggested by the interactions, control children and children with SLI were only significantly different for high MLUs (PPC, $F(1,14)=21.226, p=.0004, \eta^{2}=.60$; PCC, $F(1,14)=11.692, p=.004 \eta^{2}=.45$ and PVC, $F(1,14)=39.256, p<.0001 \eta^{2}=$ .74 ) but not for low MLUs (PPC, $F(1,14)=.190, \mathrm{p}=.67$; PCC, $F(1,14)=.454, \mathrm{p}=$ $.51 ; \mathrm{PVC}, F(1,14)=.626, \mathrm{p}=.44)$.

\section{Discussion}

The main goal of this article was to confirm that French-speaking children with SLI have a specific difficulty with phonology compared to control children matched on language level. As stated earlier, similar results have been observed for other languages such as English, Italian, Hebrew, Spanish and Catalan (Bortolini \& Leonard, 2000; Aguilar-Mediavilla et al., 2002) and this article aimed to ascertain whether these findings apply in the same way to the French language. A secondary objective was to examine the influence of language level on phonological abilities, as phonological difficulties can occur in the language of very young children or emerge later during development.

This discussion keeps to the order of the presentation of the results, with four levels of syntactic analysis: utterances, words, syllables and phonemes.

\subsection{Utterances}

No differences were found at utterance level between children with SLI and control children. The sole effect identified, for both phonemically transcribable and intelligible utterances, was a significant MLU effect. Children with longer utterances were more easily understandable, and, when language level was controlled, no difference was found between children with SLI and children with normallydeveloping language. The results with control children matched the results of Roberts, Rescorla, Giroux, and Stevens (1998) who found that intelligibility greatly improved between age two and three in children with normally-developing language. These authors found a difference between children with SLI and their control children, but these children were age-matched, not language level-matched (respective MLU of 2.4 and 4.14). Our results seem to indicate that the relative unintelligibility of children with SLI is more a consequence of their general level of language development, rather than a phonological deficit. 


\subsection{Words}

The group of children with SLI and a low MLU and the control group with a low MLU produce a similar percentage of words that match the expected adult pronunciation. With older children, however, a difference emerges and control children with high MLU are less prone to phonological mismatches than high MLU children with SLI. These results may be explained by the absence of any development in phonological performance in the children with SLI, in contrast to the two control groups, where there is a big improvement in phonological performance at the higher MLU level. There is little data in the literature comparing children with SLI and control children matched by language level at very low MLU levels. Schwartz et al. (1980) obtained the same results, but with a smaller number of children, whereas Aguilar-Mediavilla et al. (2002) obtained different results. Further research in this direction is obviously needed to confirm the existence or not of a specific phonological deficit in very young children with SLI.

The results for control children matched the results obtained for Italian- and English-speaking children, as did the results for children with high MLU. The only difference is that Bortolini and Leonard obtained lower percentages of correct word production (43.44\% for English SLI, 78.33\% for English controls, 54.33\% for Italian SLI, 79.08\% for Italian controls, as compared with $74.50 \%$ for French SLI, and $89.90 \%$ for French controls). However, the difference could come from the fact that in Bortolini and Leonard's study, the children's language was induced whereas in the current study language was spontaneous. When they are speaking spontaneously, children tend to choose words they find easier to pronounce (Leonard, Schwartz, Allen, Swanson, \& Froem-Loeb, 1989). However, this strategy does not provide them with error-free pronunciation and the same difference is found between children with SLI and control children. Finally, similar results (Owen et al., 2001) were found for Hebrew-speaking children (67.13\% for Hebrew SLI vs. 79,96 for language controls), but once again, the slightly different procedure makes it impossible to compare the results precisely.

\subsection{Syllables}

There are different ways to measure the quality of children's syllable production. Three different cues were taken into account: how closely they adhered to the number of syllable of a target word, how the syllable frames were distributed and the percentage of correct syllable frames for each syllable frame. The results can be summarized as follows:

a When the children with SLI produced a word, they were globally less effective in keeping to the target number of syllables of the word. They made significantly more omissions and additions of syllables than their peers. This seemed not to be influenced by their language level.

- Conversely, the distribution of the syllables frames produced was influenced by the language level: the proportion of simple syllables $(\mathrm{CV}, \mathrm{V})$ decreased with MLU while more complex syllabic structures (CCV, CVC) increased. Children with SLI did not differ from control children, with the exception of $\mathrm{V}$ and CVC syllables. 
a Finally, the analysis of percentages of correct syllable frame for each syllable frame did not lead to many significant results: the production of CV syllables only seemed to improve with language level and the control group seemed to perform better than the children with SLI.

It was important to look more closely at one specific type of mismatch, the omission of weak syllables, as some authors stress the importance of the number of omitted unstressed syllables as a possible marker of specific language impairment. In most languages, functional words are unstressed syllables. This is not exactly the case in French, as stress is not highly salient. Nonetheless, initial syllables are less salient that final syllables which are the syllables that carry stress in French, and most functional markers are initial syllables -at least in young children's speech. There was indeed an effect of type for initial syllables (see Table 3), but no effect of age, which showed that non-stressed syllables are produced correctly in control children at a very young age.

It is possible to compare the omission of initial syllables in French with findings for English, Italian (Bortolini \& Leonard, 2000), and Spanish-Catalan (AguilarMediavilla et al., 2002). French omission results (5.4\% for SLI, 2.7 for controls) are similar to figures for Italian (10\% and 2\%, respectively) and figures for SpanishCatalan $(9.8 \%$ and $4.6 \%$, respectively), but are very different from figures for English ( $85 \%$ and $20 \%$, respectively), which would suggest that there is something common either to the phonology or morphology of Romance languages that makes initial syllables much more salient in these languages than they are in English. This may also explain why there are weaker effects in syllable omissions than in word errors.

The distribution of syllable frames showed few type effects . Most were MLU effects which demonstrated that the complexity of the syllables tends to increase with language development. It is interesting to note that the distribution in frames at age $4 ; 0$ is very close to that found in French-speaking adults (Wioland, 1991), with the exception of CCV syllables which are much more frequent in adult language. It is important to stress that these syllables are produced in small quantities in target words, which could mean that children tend to avoid these syllables. This effect could be so strong that the older children achieved worse results in CCV syllables than their younger counterparts probably because as they become older they could not avoid these syllables anymore.

This seems to be confirmed by the third analysis of syllable production, which gives the percentages of correct production of syllable frames (see Table 5). Only the most frequent category, CV syllables, has significant results for MLU and for type, but no interaction. The results obtained in French are quite high and better than the results obtained for Spanish-Catalan (Aguilar-Mediavilla et al., 2002), which proves once again that syllable structure is developed early in the French language, or that French children are better at avoiding difficult words. It would appear difficult to use syllable production as an indicator of language deficit for French.

\subsection{Phonemes}

The results obtained for PPC and PVC went in the same direction as those obtained for words. There were large effects of type (SLI vs. control) and MLU (low 
vs. high) as well as an interaction effect and significant difference was found only between the older control children and all the other children, not between young children with SLI and young control children. The results for PCC went in the same direction but the interaction was not significant, due to a high degree of variability.

A comparison of these results with the results obtained for Spanish-Catalanspeaking children (Aguilar-Mediavilla et al., 2002) shows similar values for PCC (72.2\% for French SLI, 80.7\% for French controls, $69.2 \%$ for Spanish-Catalan SLI and $81 \%$ for Spanish-Catalan controls) and for PVC (83.3\% for French SLI, 90.0\% for French controls, $85.2 \%$ for Spanish-Catalan SLI, and 91.8\% for Spanish-Catalan controls). These results are also similar to those obtained in word repetition for PPC in Italian-speaking children ( $78 \%$ for SLI, and $96 \%$ for controls).

The major difference between the results presented above and the results in the literature is that Aguilar-Mediavilla et al. obtained significant results for young children (children with SLI aged 3 to 4 and control children aged 1;6 to 3). These authors obtained significant results for PVC and not for PCC. In others words, the performance of children with SLI was comparable to that of control children for PCC but worse for PVC. This finding does not contradict our results, which showed a more reliable effect for vowels than for consonants. Vowels could be harder than consonants for Spanish-Catalan-speaking children with SLI because they are in a bilingual environment. As the children are exposed to two different vowel systems (Catalan has more vowels than Spanish), this could create some confusion about which vowels are most prototypical and impair the phonology of children with SLI.

\section{Conclusion}

The main goal of this paper was to confirm whether French children with SLI have limited phonological ability as compared with normally-developing children matched by MLU and phonemic inventory size. The study was carried out using spontaneous language to give the SLI children the greatest chance of performing well, as it is possible for them to avoid unnecessary complex phonological constructions when they speak spontaneously, but not during a language-induced task.

Nevertheless, the results showed that there was clearly a specific limitation in the phonological abilities of French children with SLI, as had already been demonstrated for English, Hebrew, Italian, and Spanish-Catalan. Two unexpected results were also obtained, which are specific to the current study.

The first was that a significant difference between children with SLI and control children could be found only for older children (MLU above 3), not for younger children (MLU below 3). This was true for most measures -utterances, words, and phonemes, but not syllables. This result was not obtained by Aguilar-Mediavilla et al. (2002), who found a difference in children as young as the youngest children in this study. It is yet not clear why no difference was obtained. The results could possibly become significant with a larger sample of children. It is true that, more often than not, the results of young children with SLI were not as good as the results of their counterparts, but they were not significantly different. It is also true that results were highly significant in older children, with nearly no methodological difference between the two groups. The only difference was that the language was more spontaneous with young children than with older children. Even though the older children could freely 
choose the language they produced, answering specific questions necessarily leads to the use of more diverse vocabulary and syntactic forms. Another explanation could be that there is a developmental effect. This needs verifying by means of a longitudinal study with a truly developmental design, as our results showed that there was often no difference between younger and older children with SLI. It is true however that older children with SLI produced more complex language, so that they needed more advanced phonological abilities to achieve the same results. But this was not a problem for normally-developing children.

These findings lead us to put forward two hypotheses: (1) Young children with SLI have a similar phonological deficit to older children, but this deficit has no obvious consequences as long as words can be learned as unanalysed wholes (Swingley \& Aslin, 2000) and the size of their lexicon is still small; when children get older, this deficit has greater consequences as fine-grained analyses of phonological structures are necessary for morphosyntactic processing and for lexical diversification. (2) Young children have no specific phonological deficit but they are unable to develop -or fully develop-complex phonological skills which become increasingly necessary as the use of language increases in complexity. They may have deficits in some basic processes such as memory or sequential computation capacity that have consequences upon phonological processes, but not before a certain level of language complexity is reached.

This highlights the importance of conducting a developmental study (see also Goswami, 2003) which would make it possible to rule out such factors as individual child variability with more certainty. This would also promote the use of inducedlanguage experiments as well as perception experiments for example; it is clearly necessary to take a closer look at the phonological details in order to identify a potential deficit in younger children and to follow the development -impaired or notof specific features. Our results give us material which can be used in further longitudinal research.

The second unexpected result may lead to proposals that will help to test specific phonological abilities. We found that deficits are much more important at the phoneme level than at the syllable level. This can be explained for the French language by the fact that French has very regular pronunciation of syllables, which make them easier to segment.

Measures that reflected phonological processing seemed to provide a more clear-cut differentiation between children with SLI and control children. In our study, among the phonological measures, percentage of vowels correct gave the most significant results. This is interesting because it may provide speech pathologists with a more sensitive tool for diagnosing serious difficulty in phonological processing, which can lead to specific language impairment. 


\section{References}

AGUILAR-MEDIAVILLA, E., SANZ-TORRENT, M. and SERRA-RAVENTOS, M., 2002. A comparative study of the phonology of pre-school children with specific language impairment (SLI), language delay (LD) and normal acquisition. Clinical Linguistics \& Phonetics, 16 , 573-596.

BEERS, M., 1995. The phonology of normally developing and language-impaired children, Studies on Language and Language Use, Vol. 20. (Amsterdam: IFOTT). BENASICH, A. A. and TALLAL, P., 2002. Infant discrimination of rapid auditory cues predicts later language impairment. Behavioural Brain Research, 136, 31-49. BERNHARDT, B. H. and STEMBERGER, J. P., 1998. Handbook of phonological development. (San Diego: Academic Press).

BISHOP, D. V., 1992. The underlying nature of specific language impairment, Journal Of Child Psychology And Psychiatry, And Allied Disciplines, 33, 3-66. BISHOP, D. V., CARLYON, R. P., DEEKS, J. M. and BISHOP, S. J., 1999. Auditory temporal processing impairment: neither necessary nor sufficient for causing language impairment in children. Journal of Speech, Language and Hearing Research, 42(6), 1295-310.

BLANCHE-BENVENISTE, C., 1990. Le français parlé : études grammaticales. (Paris: Editions du CNRS).

BORNSTEIN, M. H., PAINTER, K. M. and PARK, J., 2002. Naturalistic language sampling in typically developing children. Journal of Child Language, 29, 687-699. BORTOLINI, U. and LEONARD, L. B., 2000. Phonology and children with specific language impairment: status of structural constraints in two languages. Journal of Communication Disorders, 33, 131-150.

CHABON, S. S., KENT-UDOLF, L. R. and EGOLF, D. B., 1982. The temporal reliability of Brown's mean length of utterance(MLU-M) measure with Post-Stage V children. Journal of Speech and Hearing Research, 25, 124-128.

CHEVRIE-MULLER, C., SIMON, A.-M., LE NORMAND, M.-T. and FOURNIER, S., 1997. Batterie d'évaluation psycholinguistique : BEPL. (Paris: ECPA). CHIAT, S., 2001. Mapping theories of developmental language impairment: premises, predictions, and evidence. Language and Cognitive Processes, 16, 113-142. CLAHSEN, H., BARTKE, S. and GOELLNER, S., 1997. Formal features in impaired grammars: A comparison of English and German SLI children. Journal of Neurolinguistics, 10, 151-171.

EVANS, J. L. and CRAIG, H. K., 1992. Language sample collection and analysis: interview compared to freeplay assessment contexts. Journal of Speech And Hearing Research, 35, 343-353.

GATHERCOLE, S. and BADDELEY, A., 1990. Phonological memory deficits in language disordered children: is there a causal connection? Journal of Memory and Language, 29, 336-360.

GOPNIK, M., 1997. Language deficits and genetic factors. Trends in Cognitive Sciences, 1, 5-9.

GOSWAMI, U., 2003. Why theories about developmental dyslexia require developmental designs. Trends in Congitive Sciences, 7, 534-540.

JOANISSE, M. F., 2004. Specific Language Impairments in Children: Phonology, Semantics, and the English Past Tense. Current Directions in Psychological Science, 13, 156-160. 
JOANISSE, M. F. and SEIDENBERG, M. S., 1998. Specific language impairment: a deficit in grammar or processing? Trends in Cognitive Sciences, 2, 240-247.

KLEE, T. and FITZGERALD, M. D., 1985. The relation between grammatical development and mean length of utterance in morphemes. Journal of Child Language, 12, 251-269.

KLEE, T., SCHAFFER, M., MAY, S., MEMBRINO, I. and MOUGEY, K., 1989. A comparison of the age-MLU relation in normal and specifically language-impaired preschool children. Journal of Speech and Hearing Disorders, 54, 226-233.

LE NORMAND, M. T., 1986. A developmental exploration of language used to accompany symbolic play in young, normal children (2 - 4 years old). Child: Care, Health and Development, 12, 121-134.

LEONARD, L. B., 1998. Children with specific language impairment. (Cambridge, MA: MIT Press).

LEONARD, L. B., DROMI, E., ADAM, G. and ZADUNAISKY-EHRLICH, S., 2000. Tense and finiteness in the speech of children with specific language impairment acquiring Hebrew. International journal of language communication disorders, 35, 319-335.

LEONARD, L. B., MCGREGOR, K. K. and ALLEN, G. D., 1992. Grammatical morphology and speech perception in children with specific language impairment. Journal of Speech and Hearing Research, 35, 1076-1085.

LEONARD, L. B., SCHWARTZ, R. G., ALLEN, G. D., SWANSON, L. A. and FROEM-LOEB, D., 1989. Unusual phonological behavior and the avoidance of homonymy in children. Journal of Speech and Hearing Research, 32, 583-590. MACWHINNEY, B., 2000. The CHILDES project : Tools for analyzing talk (3rd). (Hillsdale, N.J: Lawrence Erlbaum).

MACWHINNEY, B. and SNOW, C. E., 1985. The child language data exchange system. Journal of Child Language, 12, 271-296.

OWEN, A. J., DROMI, E. and LEONARD, L. B., 2001. The phonology-morphology interface in the speech of Hebrew-speaking children with specific language impairment. Journal of Communication Disorders, 34, 323-337.

PAUL, R. and JENNINGS, P., 1992. Phonological behavior in toddlers with slow expressive language development. Journal of Speech And Hearing Research, 35, 99107.

RESCORLA, L. and RATNER, N. B., 1996. Phonetic profiles of toddlers with specific expressive language impairment (SLI-E). Journal of Speech And Hearing Research, 39, 153-165.

RICE, M. L. and WEXLER, K., 1995. Extended optional infinitive (EOI) account of specific language impairment. In D. MacLaughlin \& S. McEwan (Eds.), Proceedings of the 19th annual Boston University Conference on Language Development, Vol. 2

(Somerville, MA: Cascadilla Press), pp. 451-462.

ROBERTS, J., RESCORLA, L., GIROUX, J. and STEVENS, L., 1998. Phonological skills of children with specific expressive language impairment (SLI-E): outcome at age 3. Journal of Speech, Language, And Hearing Research, 41, 374-384.

ROID, G. and MILLER, L., 1993. Leiter International Performance Scale . (Chicago IL: Stoekting).

SCHWARTZ, R. G., LEONARD, L. B., FOLGER, M. K. and WILCOX, M. J., 1980. Early phonological behavior in normal-speaking and language disordered children: evidence for a synergistic view of linguistic disorders. The Journal of Speech And Hearing Disorders, 45, 357-377. 
SHRIBERG, L. D., 1993. Four new speech and prosody-voice measures for genetics research and other studies in developmental phonological disorders. Journal of Speech And Hearing Research, 36, 105-140.

SHRIBERG, L. D., and KWIATKOWSKI, J., 1982. Phonological disorders III : A procedure for assessing severity of involvement. Journal of Speech And Hearing Disorders, 47, 256-270.

SHRIBERG, L. D., and KWIATKOWSKI, J., 1994. Developmental phonological disorders. I: A clinical profile. Journal of Speech And Hearing Research, 37, 11001126.

STARK, R. E. and TALLAL, P., 1981. Selection of children with specific language deficits. The Journal Of Speech And Hearing Disorders, 46, 114-122.

STOEL GAMMON, C., 1989. Prespeech and early speech development of two late talker. First Language, 9, 207-223.

SWINGLEY, D. and ASLIN, R. N., 2000. Spoken word recognition and lexical representation in very young children. Cognition, 76, 147-166.

TALLAL, P., STARK, R. E., and MELLITS, D., 1985. The relationship between auditory temporal analysis and receptive language development: evidence from studies of developmental language disorder. Neuropsychologia, 23, 527-534. VAN DER LELY, H. K. and CHRISTIAN, V., 2000. Lexical word formation in children with grammatical SLI: a grammar-specific versus an input-processing deficit? Cognition, 75, 33-63.

VAN DER LELY, H. K., and STOLLWERCK, L., 1997. Binding theory and grammatical specific language impairment in children. Cognition, 62, 245-90. WECHSLER, D., 1996. Echelle d'intelligence pour enfants (3ème édition). (Paris: E A P).

WIOLAND, F., 1991. Prononcer les sons du français. Des sons et des rythmes. (Paris: Hachette). 


\section{Acknowledgments}

The cooperation between the two authors was made possible by a specific grant from FNRS (Belgium) and the 'Institut National de la Santé et de la Recherche Médicale (INSERM-France)'. 
Table 1: General characteristics of the participants

\begin{tabular}{l|l|l|l}
\hline Type & Age & MLU & Phonemic inventory \\
\hline SLI- high (n=8) & & & \\
Mean (S.D.) & $8 ; 6(1 ; 1)$ & $3.7(1.5)$ & $23.1(2.75)$ \\
Range & $7 ; 1-11 ; 11$ & $2.25-5.8$ & $18-27$ \\
SLI-low (n=8) & $3 ; 11(0 ; 7)$ & $2.4(0.3)$ & $17.9(4.49)$ \\
Mean (S.D.) & $3 ; 0-5 ; 0$ & $1.98-2.55$ & $13-27$ \\
range & $4 ; 0(0)$ & $3.7(1.0)$ & $22.5(3.62)$ \\
Controls - high (n=8) & $4 ; 0-4 ; 0$ & $2.09-5.6$ & $14-26$ \\
Mean (S.D.) & & & \\
range & & & \\
& & & \\
Controls-low (n=8) & $2 ; 3(0)$ & $2.7(0.8)$ & $19.5(3.50)$ \\
Mean (S.D.) & $2 ; 3-2 ; 3$ & $1.88-4.04$ & $15-25$ \\
range & &
\end{tabular}


Table 2: Characteristics of the transcripts at utterance level

\begin{tabular}{|l|l|l|l|l|l|l|}
\hline Type & MLU & Vocalizations & $\begin{array}{l}\text { Phonemically } \\
\text { transcribable } \\
\text { utterances }\end{array}$ & $\begin{array}{l}\text { Fully } \\
\text { intelligible } \\
\text { utterances }\end{array}$ & $\begin{array}{l}\text { \% of } \\
\text { phonemically } \\
\text { transcribable } \\
\text { utterances }\end{array}$ & $\begin{array}{l}\text { \% of fully } \\
\text { intelligible } \\
\text { utterances }\end{array}$ \\
\hline SLI & High & $128(10.3)$ & $127(10.1)$ & $110(8.0)$ & $99.4(0.9)$ & $86.5(8.5)$ \\
\hline SLI & Low & $138(57.0)$ & $130(45.2)$ & $98(20.9)$ & $95.6(4.6)$ & $74.8(16.4)$ \\
\hline Controls & High & $112(23.3)$ & $110(23.3)$ & $108(22.5)$ & $98.5(1.4)$ & $96.5(2.1)$ \\
\hline Controls & Low & $164(49.4)$ & $155(46.5)$ & $121(40.4)$ & $94.5(2.4)$ & $75.0(14.9)$ \\
\hline
\end{tabular}


Table 3: Mean of added or omitted syllables (standard deviation)

\begin{tabular}{ll|lllll}
\hline Type & MLU & All & \multicolumn{2}{l}{ Addition } & Omission Initial & Final \\
omission & omission \\
\hline SLI & High & $11(5)$ & $5(2)$ & $7(4)$ & $5(3)$ & $1(1)$ \\
SLI & Low & $13(7)$ & $5(3)$ & $9(6)$ & $6(6)$ & $2(2)$ \\
Controls & High & $3(2)$ & $1(2)$ & $2(2)$ & $1(1)$ & $1(1)$ \\
Controls & Low & $11(6)$ & $4(5)$ & $7(4)$ & $4(3)$ & $2(2)$ \\
Effect of type & $9.052^{* *}$ & $4.960^{*}$ & $4.412^{*}$ & $4.546^{*}$ & $0.013^{\text {ns }}$ \\
Effect of MLU & $6.910^{*}$ & $1.548^{\text {ns }}$ & $5.687^{*}$ & $3.163^{\text {ns }}$ & $3.806^{\text {ns }}$ \\
Interaction effect & $2.110^{\text {ns }}$ & $1.318^{\text {ns }}$ & $0.881^{\text {ns }}$ & $0.383^{\text {ns }}$ & $0.989^{\text {ns }}$ \\
\hline
\end{tabular}

Note: All effect values correspond to $\mathrm{F}(1,28)$ values from ANOVAs calculations. $*=$ $\mathrm{p}<0.05, * *=\mathrm{p}<0.005, * * *=\mathrm{p}<0.0005, * * * *=\mathrm{p}<0.0001, \mathrm{~ns}=$ non significant effect. 
Table 4: Distribution of syllable frames

\begin{tabular}{|c|c|c|c|c|c|c|c|}
\hline Type & MLU & $\mathrm{CV}$ & V & $\mathrm{VC}$ & $\mathrm{CCV}$ & $\mathrm{CVC}$ & others \\
\hline SLI & High & $46(10)$ & $23(3)$ & $4(2)$ & $3(2)$ & $8(3)$ & $14(5)$ \\
\hline SLI & Low & $57(7)$ & $25(6)$ & $2(2)$ & $1(0)$ & $5(4)$ & $10(3)$ \\
\hline Controls & High & $52(3)$ & $15(3)$ & $3(1)$ & $2(1)$ & $11(2)$ & $15(2)$ \\
\hline Controls & Low & $57(6)$ & $21(6)$ & $3(3)$ & $1(1)$ & $8(4)$ & $9(3)$ \\
\hline \multicolumn{2}{|c|}{ Effect of type } & $1.79^{\mathrm{ns}}$ & $5.02^{*}$ & $3.11^{\mathrm{ns}}$ & $1.02^{\mathrm{ns}}$ & $5.51^{*}$ & $0.07^{\mathrm{ns}}$ \\
\hline \multicolumn{2}{|c|}{ Effect of MLU } & $9.61^{* *}$ & $10.74^{* *}$ & $0.798^{\mathrm{ns}}$ & $15.43^{* * *}$ & $5.48^{*}$ & $15.89^{* * * *}$ \\
\hline \multicolumn{2}{|c|}{ Interaction effect } & $1.26^{\mathrm{ns}}$ & $1.68^{\mathrm{ns}}$ & $2.33^{\mathrm{ns}}$ & $0.65^{\mathrm{ns}}$ & $0.02^{\mathrm{ns}}$ & $0.58^{\mathrm{ns}}$ \\
\hline
\end{tabular}


Table 5: Percentages of correct responses for each syllable frame

\begin{tabular}{ll|llllll}
\hline Type & MLU & CV & V & VC & CCV & CVC & others \\
\hline SLI & High & $95(4)$ & $98(2)$ & $65(23)$ & $71(37)$ & $75(24)$ & $77(8)$ \\
SLI & Low & $91(4)$ & $99(1)$ & $71(34)$ & $50(47)$ & $51(26)$ & $61(19)$ \\
Controls & High & $98(1)$ & $100(0)$ & $96(6)$ & $69(21)$ & $94(7)$ & $92(6)$ \\
Controls & Low & $94(3)$ & $97(3)$ & $65(42)$ & $82(35)$ & $64(21)$ & $58(11)$ \\
Effect of type & $5.97^{*}$ & $0.07^{\text {ns }}$ & $1.43^{\text {ns }}$ & $1.421^{\text {ns }}$ & $4.71^{\text {ns }}$ & $1.51^{\text {ns }}$ \\
Effect of MLU & $11.61^{* *}$ & $2.326^{\text {ns }}$ & $1.41^{\text {ns }}$ & $0.09^{\text {ns }}$ & $13.22^{* *}$ & $35.56^{* * * *}$ \\
Interaction effect & $0.02^{\text {ns }}$ & $6.189^{*}$ & $3.05^{\text {ns }}$ & $1.76^{\text {ns }}$ & $0.14^{\text {ns }}$ & $5.45^{*}$ \\
\hline
\end{tabular}

Note: All effect values correspond to $\mathrm{F}(1,28)$ values from ANOVAs calculations. * $\mathrm{p}<0.05, * *=\mathrm{p}<0.005, * * *=\mathrm{p}<0.0005, * * * *=\mathrm{p}<0.0001, \mathrm{~ns}=$ non significant effect. 
Table 6: Percentages of phonemes correct, consonants correct, and vowels correct

\begin{tabular}{ll|lll}
\hline Type & MLU & PPC & PCC & PVC \\
\hline SLI & High & $80.3(6.9)$ & $75.9(10.1)$ & $84.7(5.1)$ \\
SLI & Low & $75.5(5.9)$ & $68.5(9.8)$ & $82.0(4.7)$ \\
Controls & High & $92.6(3.0)$ & $89.3(4.7)$ & $96.3(1.2)$ \\
Controls & Low & $77.0(7.5)$ & $72.1(11.3)$ & $83.8(4.2)$ \\
Effect of type & $10.20^{* *}$ & $6.68^{*}$ & $21.48^{* * * *}$ \\
Effect of & MLU & $22.39^{* * *}$ & $14.05^{* *}$ & $27.64^{* * * *}$ \\
\multicolumn{2}{l}{ Interaction effect } & $6.23^{*}$ & $2.26^{\text {ns }}$ & $11.72^{* *}$ \\
\hline
\end{tabular}

Note: All effect values correspond to $\mathrm{F}(1,28)$ values from ANOVAs calculations. * $\mathrm{p}<0.05, * *=\mathrm{p}<0.005, * * *=\mathrm{p}<0.0005, * * * *=\mathrm{p}<0.0001, \mathrm{~ns}=$ non significant effect. 
Figure caption

Figure 1: Percentage of words correctly produced 
Figure 1: Percentage of words correctly produced

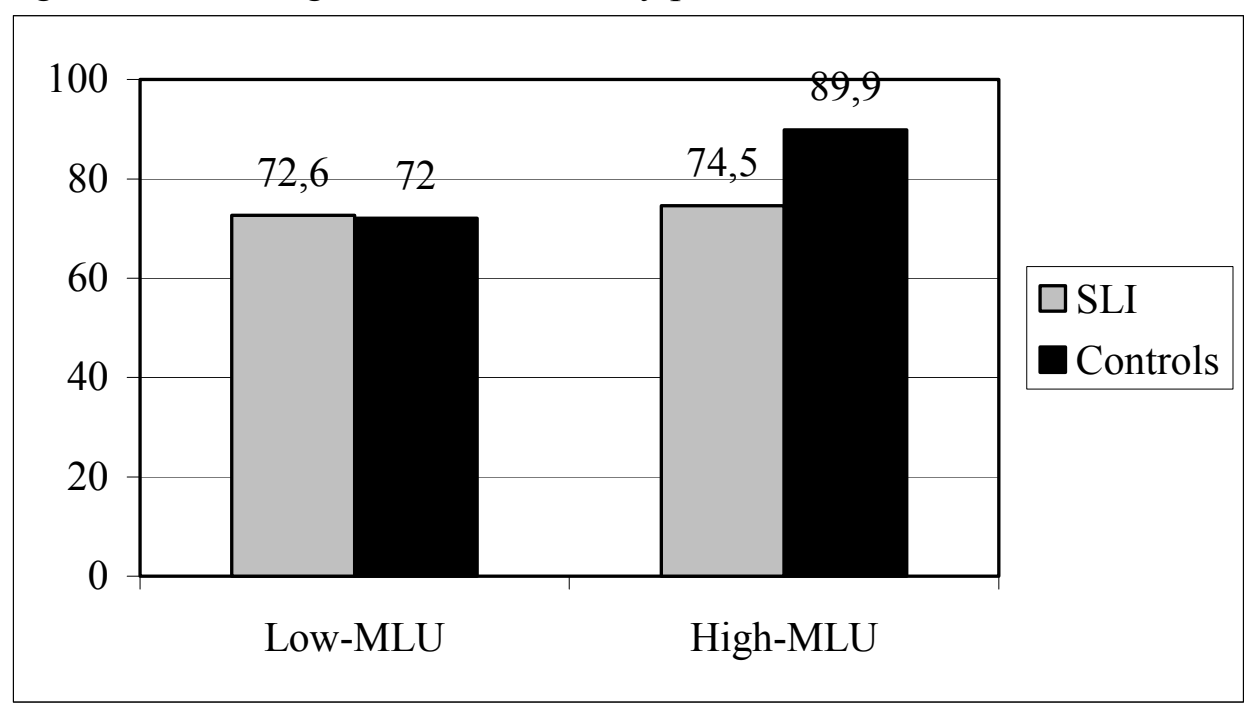


Appendix: Phonemic system of the French language

\begin{tabular}{lllll}
\hline $\begin{array}{l}\text { SAMPA } \\
\text { symbol }\end{array}$ & $\begin{array}{l}\text { API } \\
\text { symbol }\end{array}$ & $\begin{array}{l}\text { simplified French word } \\
\text { phonemic } \\
\text { set }\end{array}$ & $\begin{array}{l}\text { phonemic } \\
\text { transcription }\end{array}$ & $\begin{array}{l}\text { English } \\
\text { translation }\end{array}$ \\
\hline
\end{tabular}

Consonants

\section{Plosives}

\begin{tabular}{lllll}
$\mathrm{p}$ & $\mathrm{P}$ & pont & po $~$ & bridge \\
$\mathrm{b}$ & $\mathrm{B}$ & bon & bo & good \\
$\mathrm{t}$ & $\mathrm{T}$ & temps & ta & weather \\
$\mathrm{d}$ & $\mathrm{D}$ & dans & $\mathrm{da} \sim$ & into \\
$\mathrm{k}$ & $\mathrm{K}$ & quand & $\mathrm{ka} \sim$ & when \\
$\mathrm{g}$ & $\mathrm{G}$ & gant & ga & glove \\
\hline
\end{tabular}

\section{Fricatives}

\begin{tabular}{|c|c|c|c|c|}
\hline$f$ & $F$ & femme & fam & woman \\
\hline V & V & vent & $\mathrm{va} \sim$ & wind \\
\hline S & $S$ & sans & $\mathrm{sa} \sim$ & without \\
\hline $\mathrm{Z}$ & Z & zone & zon & zone \\
\hline $\mathrm{S}$ & $\int$ & champ & $\mathrm{Sa} \sim$ & field \\
\hline Z & 3 & gens & $\mathrm{Za} \sim$ & people \\
\hline \multicolumn{5}{|c|}{ Nasals } \\
\hline $\mathrm{m}$ & $M$ & mon & mo & my \\
\hline $\mathrm{n}$ & $\mathrm{N}$ & nom & no $\sim$ & name \\
\hline $\mathrm{J}$ & $\mathrm{n}$ & oignon & $\mathrm{oJ} O \sim$ & oignon \\
\hline $\mathrm{N}$ & $\eta$ & camping & ka $\sim \mathrm{piN}$ & camping \\
\hline \multicolumn{5}{|c|}{ Liquids } \\
\hline 1 & $L$ & long & lo $\sim$ & long \\
\hline $\mathrm{R}$ & $\mathrm{R}$ & rond & Ro & round \\
\hline
\end{tabular}

Vowels glides 


\begin{tabular}{lllll} 
w & w & coin & kwe & coin \\
$\mathrm{H}$ & $\mathrm{u}$ & juin & ZHe & june \\
$\mathrm{j}$ & $\mathrm{j}$ & pierre & pjER & stone \\
\hline
\end{tabular}

\section{Vowels}

\section{Oral vowels}

\begin{tabular}{|c|c|c|c|c|c|}
\hline I & I & & si & si & if \\
\hline $\mathrm{e}$ & $\mathrm{e}$ & $\mathrm{E} /$ & ses & se & her \\
\hline $\mathrm{E}$ & $\varepsilon$ & $\mathrm{E} /$ & seize & $\mathrm{sEz}$ & sixteen \\
\hline $\mathrm{a}$ & $a$ & $\mathrm{~A} /$ & patte & pat & pawn \\
\hline A & $a$ & $\mathrm{~A} /$ & pâte & $\mathrm{pAt}$ & dough \\
\hline $\mathrm{O}$ & 0 & $\mathrm{O} /$ & comme & $\mathrm{kOm}$ & as \\
\hline o & 0 & $\mathrm{O} /$ & gros & gRo & big \\
\hline $\mathrm{u}$ & $\mathrm{u}$ & & doux & $\mathrm{du}$ & soft \\
\hline y & $y$ & & $\mathrm{du}$ & dy & of \\
\hline 2 & $\varnothing$ & $\& /$ & deux & $\mathrm{d} 2$ & two \\
\hline 9 & $œ$ & $\& /$ & neuf & n9f & nine \\
\hline (a) & $\vartheta$ & $\& /$ & justement & Zyst@ma & rightly \\
\hline \multicolumn{6}{|c|}{ Nasal vowels } \\
\hline $\mathrm{e} \sim$ & $\sim \varepsilon$ & $\mathrm{U} \sim /$ & vin & ve $\sim$ & vine \\
\hline $\mathrm{a} \sim$ & $\tilde{a}$ & & vent & $\mathrm{va} \sim$ & wind \\
\hline $0 \sim$ & õ & & bon & bo $\sim$ & good \\
\hline $9 \sim$ & $\sim œ$ & $\mathrm{U} \sim /$ & brun & bR9 & brown \\
\hline
\end{tabular}

Note: This description is adapted from the SAMPA for French description (see http://www.phon.ucl.ac.uk/home/sampa/french.htm). 